\title{
A LITERATURA EM LIVROS DIDÁTICOS DO ENSINO MÉDIO À LUZ DO LETRAMENTO LITERÁRIO
}

\section{THE LITERATURE IN TEACHING BOOKS OF MEDIUM EDUCATION IN THE LIGHT OF LITERARY LITERAR}

\author{
Cláudia Fernanda Freitas Maia \\ Rosana Baptista dos Santos
}

\begin{abstract}
RESUMO: Este artigo apresenta os resultados de uma pesquisa desenvolvida no mestrado profissional em Educação pela Universidade Federal dos Vales do Jequitinhonha e Mucuri, cujo propósito foi examinar a metodologia de ensino da literatura em livros didáticos de Língua Portuguesa do ensino médio da rede particular e da pública, verificando, sobretudo, as propostas de ensino do conto, com base na Lei de Diretrizes e Bases da Educação Nacional (1996), nos Parâmetros Curriculares Nacionais do Ensino Médio (2002), nas Orientações Curriculares para o Ensino Médio (2006) e na Base Nacional Comum Curricular (2016). Para tanto, investigou-se a transposição do conto do suporte original para o livro didático, bem como as propostas de atividades de leitura e compreensão dos textos apresentadas em tais livros. A hipótese é que o conto foi apresentado de modo fragmentado nessas coleções, o que impossibilitaria a concretização do letramento literário nessa fase de ensino. Esta pesquisa é de cunho quanti-qualitativo e se desdobrou nas seguintes fases: uma pesquisa bibliográfica e uma pesquisa documental, durante a qual foi feita a coleta de dados, cujos livros didáticos analisados são os seguintes: Coleção Estudo - Língua Portuguesa (2016), de Flávia Roque, volumes I, II, III e IV do $1^{\circ}, 2^{\circ}$ e $3^{\circ}$ anos e Português: contexto, interlocução e sentido (2013), de Maria Luiza M. Abaurre, volumes I, II e III. Tal estudo justifica-se porque o ensino do conto é relevante nas aulas de literatura no ensino médio, pois aproxima o leitor da literatura, bem como valoriza o caráter humanizador desse conteúdo curricular. Os resultados desta pesquisa demonstraram que não há uma escolarização adequada da literatura por meio dos manuais didáticos A e B. Por isso, espera-se que esse estudo possa contribuir para se repensar a literatura no ensino médio, principalmente, no que diz respeito à formação do leitor literário e ao letramento literário a partir do uso dos livros didáticos de Língua Portuguesa.
\end{abstract}

Palavras-chave: Conto. Ensino de literatura. Livros didáticos. Letramento literário.

ABSTRACT: This article presents the results of research developed in the masters in Education of the Federal University of the Jequitinhonha and Mucuri Valleys, examined the methodology of literature teaching in Portuguese Language textbooks within the high school private and public education systems, verifying how the tale teaching happens, based on the Brazilian Portuguese Initials for Law of Directives and Bases of National Education (1996), the Brazilian Portuguese Initials for High School National Curricular Parameters (2002), and also based on the Brazilian Portuguese Initials for High School Curriculum Guidelines (2006) and the Brazilian Portuguese Initials for National Common Basic Curriculum (2016) . For this purpose, it was investigated the transposition of the supporting original story into the textbook, as well as the reading

Educação, Psicologia e Interfaces, Volume 2, Número 1, p. 6-21, Janeiro/Abril, 2018

ISSN: 2594-5343 DOI: https://doi.org/10.37444/issn-2594-5343.v2i1.59 
activities and text comprehension purposes brought in those books. The hypothesis is that the tale was presented in a fragmented way in those collections, which may make it impossible to achieve the literary literacy at this stage of teaching. This is a quantitativequalitative research and it was unfolded in the following phases: a bibliographical research and a documentary one, during which the data collection was accomplished, and the textbooks are the ones as follows: "Coleção Estudo - Lingua Portuguesa (2016)" by Flavia Roque, volumes I, II, III and IV, from the freshman to the senior years and "Português: contexto, interlocução e sentido (2013)" by Maria Luiza M. Abaurre, volumes I, II and III. This study is justified by the fact that the tale teaching is relevant into the literature classes in high school, because not only does it approach the literature reader but it also values the humanizing character of curriculum content. The results of the present research point out that there isn't an adequate schooling through the A and B textbooks. Therefore, it is expected from this study to contribute to the rethinking of literature in high school, especially concerning the literary reader and the literary literacy, by using Portuguese Language textbooks.

Keywords: Tale. Literature teaching. Textbooks. Literary literacy.

\section{INTRODUÇÃO}

Este artigo apresenta os resultados de uma pesquisa desenvolvida no Mestrado Profissional em Educação da Universidade Federal dos Vales do Jequitinhonha e Mucuri, cujo tema relaciona-se ao estudo sobre o ensino de literatura em livros didáticos do ensino médio, a saber: Coleção Estudo - Língua Portuguesa (2016), de Flávia Roque, volumes I, II, III e IV do $1^{\circ}, 2^{\circ}$ e $3^{\circ}$ anos e Português: contexto, interlocução e sentido (2013), de Maria Luiza M. Abaurre, volumes I, II e III, denominadas, respectivamente, como A (rede particular - 2016) e B (rede pública - 2013). Ambas foram utilizadas por escolas da região de Montes Claros-MG. O problema central deste estudo refere-se à metodologia de ensino do conto em livros didáticos do ensino médio, uma vez que ele é trabalhado de uma maneira fragmentada, sendo utilizado como pretexto, na maioria das vezes, para seleção de itens gramaticais ou até mesmo para atividades de leitura e compreensão de textos.

Partindo do pressuposto de que o ensino de Literatura na escola é imprescindível para a formação de leitores e até mesmo cidadãos críticos e reflexivos, à medida que provoca no aluno o prazer pela leitura, analisou-se o ensino do conto em duas coleções didáticas de Língua Portuguesa do ensino médio da rede particular e pública, a fim de verificar como tal gênero é trabalhado. Considerando a relevância do letramento

Educação, Psicologia e Interfaces, Volume 2, Número 1, p. 6-21, Janeiro/Abril, 2018 ISSN: 2594-5343 DOI: https://doi.org/10.37444/issn-2594-5343.v2i1.59 
literário, buscou-se responder aos seguintes questionamentos: como o ensino do conto é tratado nos livros didáticos? A forma como o conto é ensinado possibilita a concretização do letramento literário? Tais indagações proporcionam reflexões que nortearam a pesquisa acerca da escolarização adequada do ensino de Literatura na escola.

Nesse sentido, antes mesmo de tratar do conceito de letramento literário, faz-se necessário refletir a respeito da literatura enquanto objeto de ensino e instrumento de liberdade que deveria ser proposto nos currículos escolares. É preciso ressaltar que, segundo Antonio Candido (1995), ao refletir sobre o que seria a literatura, bem como a respeito do seu caráter humanizador, concluiu-se que a literatura é fundamental na vida do homem, visto que pode transformá-lo num sujeito mais humano, capaz de entender o mundo e a si mesmo.

É necessário salientar que o objetivo geral deste trabalho é investigar como se propõe o ensino do conto em livros didáticos do ensino médio. Há que se ressaltar que o ensino do conto e da literatura em materiais didáticos, em geral, acontece de modo fragmentado, primando pela periodização literária em detrimento da estrutura do texto. Além disso, como objetivos específicos, realizou-se a análise da transferência do suporte do conto para o livro didático, bem como a seleção do fragmento que compõe a lição das atividades de leitura e interpretação do conto. Com isso, pretendeu-se observar a possibilidade do desenvolvimento ou não do letramento literário por meio das propostas de ensino.

Essa pesquisa justifica-se porque o ensino do conto em livros didáticos do ensino médio deveria priorizar as características da literatura enquanto obra de arte verbal que conduz o indivíduo ao reconhecimento do mundo e de si mesmo. É habitual encontrar nos livros didáticos narrativas que, ao terem partes de seus textos transferidos para o livro, revelam a falta de uma determinada sequência que compõe o sentido global do texto como, por exemplo, o clímax ou a exposição.

Vale destacar que, para que o (a) aluno (a) possa compreender de modo adequado os textos literários com os quais lidará durante toda a sua vida, far-se-á necessário que as aulas de Literatura estejam articuladas com as práticas significativas de leitura na escola, a qual não é a única instituição responsável por propiciar o letramento literário. Há que se destacar que, segundo Rildo Cosson (2014a), o

Educação, Psicologia e Interfaces, Volume 2, Número 1, p. 6-21, Janeiro/Abril, 2018 
letramento inicia-se antes mesmo do processo de escolarização. Logo, o trabalho de leitura do texto literário deve envolver tanto o cânone literário quanto os textos ainda não canônicos, pois uma escolarização adequada da leitura literária pressupõe despertar o interesse do aluno (a) pela obra e pelo autor.

Os resultados obtidos a partir das reflexões produzidas ao longo desta pesquisa podem contribuir para que os docentes da área de Linguagens e Códigos reflitam sobre o uso adequado dos livros didáticos, mas também como a prática da leitura da literatura deve ser mediada pelo professor de modo a favorecer a concretização do letramento literário. Para isso, a fim de evitar que o aluno construa conceitos inadequados de texto literário e até mesmo de narrativa, é preciso que os materiais didáticos de Língua Portuguesa atentem para a adequação do texto literário e ao que, de fato, a literatura demanda enquanto disciplina que propicia ao leitor uma representação do mundo e de si mesmo.

\section{MATERIAL E MÉTODO}

A pesquisa desenvolveu-se por meio de cunho bibliográfico e quanti-qualitativo, utilizando-se da análise documental. A investigação centrou-se na incidência e na forma como os contos aparecem nas coleções, bem como da interpretação dos dados coletados mediante as teorias selecionadas para fundamentação do trabalho. Contudo, vale destacar que, embora esta pesquisa seja quanti-qualitativa, a abordagem predominante é qualitativa, haja vista as próprias etapas de procedimentos técnicos relacionados a ela.

A forma como os contos são apresentados nos livros didáticos assume papel fundamental nesta pesquisa pelo fato de aparecerem ora fragmentados, ora na íntegra. Dessa forma, foram estipuladas as seguintes etapas para a coleta de dados:

1) Seleção dos contos nos livros didáticos;

2) Verificação de quais as características gerais dos livros didáticos (suporte em que o conto é veiculado, sua configuração geral, título e faixa etária etc.);

3) Exame da estrutura interna dos textos, de modo a identificar se estariam completos, se seriam contos ou partes de um romance, por exemplo;

4) Análise das adequações demandadas para a transposição do texto literário de seu suporte original para o livro didático;

Educação, Psicologia e Interfaces, Volume 2, Número 1, p. 6-21, Janeiro/Abril, 2018

ISSN: $2594-5343$ DOI: https://doi.org/10.37444//issn-2594-5343.v2i1.59 
5) Análise das propostas de leitura e as atividades de compreensão que são apresentadas no livro didático para o trabalho com o texto literário.

O método adotado é o indutivo, o qual "[...] procede inversamente ao dedutivo: parte do particular e coloca a generalização como um produto posterior do trabalho de coleta de dados particulares." (GIL, 2008, p. 10). Esse método apresenta grande relevância no que concerne aos estudos relacionados à área da educação, principalmente no caso desta pesquisa, uma vez que trata de investigar o ensino do conto em livros didáticos de Língua Portuguesa. Para atingir aos objetivos da pesquisa, foram produzidos critérios para análise das coleções didáticas. Esse roteiro está subdividido em itens que contemplam as diretrizes para o ensino de literatura e se organizam em uma escala com quatro níveis, quais sejam: 1. sim; 2. não; 3. parcialmente; 4. sempre.

Após esses critérios, reunimos as informações coletadas em tabelas que demonstram a cada volume por ano no caso da coleção A e nos volumes únicos da B que a incidência das respostas traça o percurso das análises em relação ao ensino de literatura. Foi necessário, também, criarmos gráficos no formato de colunas que se tornaram de grande valia para este estudo, porque apontam para as diferenças e semelhanças existentes no que se referem ao ensino do conto nos livros analisados de modo mais explícito.

\section{RESULTADOS E DISCUSSÃO}

A análise foi realizada a partir do estudo sobre o ensino de literatura, envolvendo as questões que se referem ao processo de leitura e à formação do leitor literário, cuja escolarização adequada promove a concretização do letramento literário no ensino médio. Contudo, como esse letramento envolve práticas sociais de leitura e escrita, ele encontra fundamentação no que tange às finalidades para o ensino de literatura no ensino médio, através dos seguintes documentos oficiais que regem tal prática: Lei de Diretrizes e Bases da Educação Nacional - LDBEN (1996), Parâmetros Curriculares Nacionais do Ensino Médio - PCNEM (2002), Orientações Curriculares do Ensino Médio - OCEM (2006), Base Nacional Comum Curricular - BNCC (2016) e Programa Nacional do Livro Didático - PNLD (2015). Logo, fizemos um estudo comparativo dos contos apresentados nas coleções A e B. 


\subsection{Propostas de ensino: o conto nas coleções A e B}

Os contos que compõem as coleções A e B são apresentados por meio de excertos, o que dificulta o seu entendimento no que se referem aos elementos principais da narrativa, quais sejam: tempo, espaço, enredo, narrador e personagem. A fim de elucidar como os contos são apresentados nos três anos do ensino médio na primeira coleção (Gráfico 1).

Gráfico 01. Total de contos por ano.

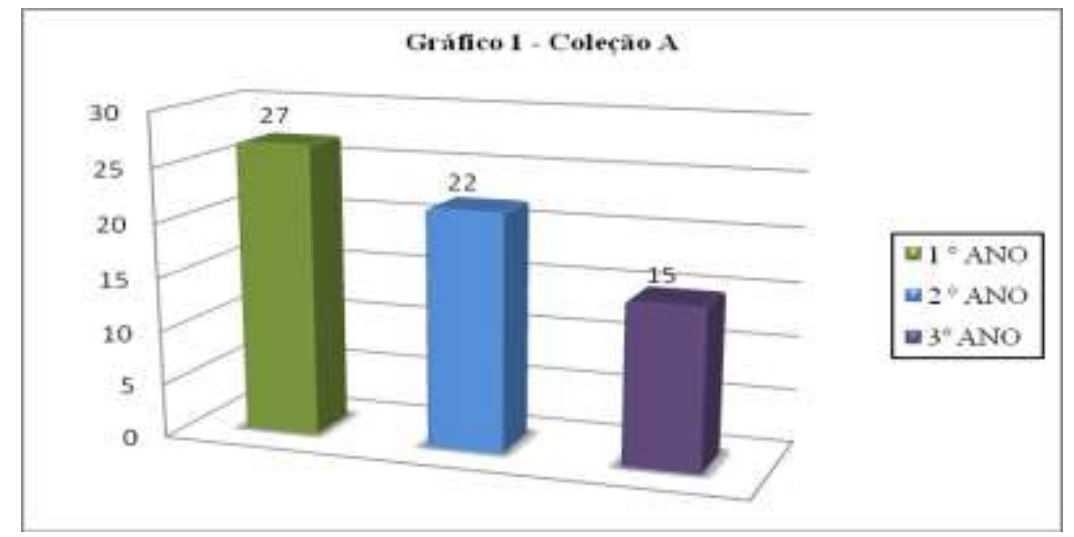

Fonte: dados da pesquisa, 2017.

Verifica-se que a maior quantidade de contos está concentrada no primeiro ano e a menor quantidade se apresenta no terceiro ano do ensino médio. Infere-se que, à medida que o aluno avança em seus estudos, o gênero conto tende a reduzir no último ano do ensino médio. Isso pode ser decorrente do próprio currículo da disciplina de Língua Portuguesa que enfatiza os conteúdos de ensino, no caso dessa coleção, voltados para o Exame Nacional do Ensino Médio - ENEM - e outros vestibulares que esses alunos leitores têm de concorrer ao final do ensino médio. Os poucos contos que aparecem nos volumes do terceiro ano são, em sua maioria, fragmentados e priorizam as matérias que são cobradas nos vestibulares, como é o caso do conto de Machado de Assis, intitulado Pai contra mãe:

Figura 01. Pai contra mãe - Machado de Assis

Educação, Psicologia e Interfaces, Volume 2, Número 1, p. 6-21, Janeiro/Abril, 2018 
02. (UFES) Quem perdia um escravo por fuga dava algum dinheiro a quem tho levasse. Punha anúncios nas folhas públicas, com os sinais do fugido, o nome, a roupa, o defeito físico, se o tinha, o bairro por onde andava e a quantia de gratificasáo. [...] Protestava-se com todo o rigor da tei contra quem o acoitasse.

ASsis, Machado de. Pai contra mae. In: Reliquias de casa veltha, 1906.

Com relagaio ao texto, é CORRETO afirmar que

(x) em "se o tinha"; o "se" é o meamo da frase "se alguem pendia um escravo, dava dinheiro a quem tho devolvesse."

B) em "se o tinha", o "so" tem a mesma funç̄o do "se" na frase "protestava-se com toda o rigor da lei".

C) em "Protestava-se cam todo o rigor da lei", o "se" pode ser eliminado sem prejuizo do sentido.

D) o "o" do "o tinha" tem a mesma classe gramatical do "o" de "o bairro".

E) em "todo o rigor da lei", o "o" tem a mesma classe gramatical do "o" em "quem o acoitasse".

Fonte: Coleção A $-3^{\circ}$ ano - Vol. IV.

Esse fragmento é utilizado como suporte para estudo das classes gramaticais em um determinado exercício da parte de Gramática da coleção em estudo. Também faltam alguns elementos da narrativa, o que prejudica o sentido do texto literário, pois a ausência de outras informações que remetem à estrutura interna do conto dificulta o entendimento do leitor quanto ao sentido do texto literário em sua totalidade. Quanto à segunda coleção, observou-se algumas distinções no que diz respeito à primeira (Gráfico 2).

Gráfico 2. Total de contos por ano.

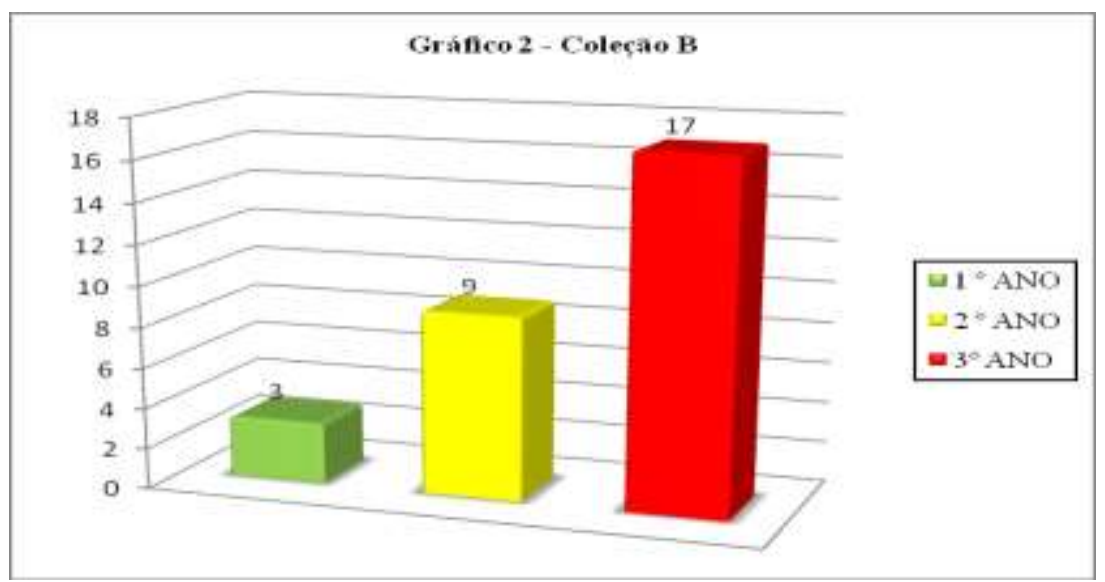

Fonte: Dados da pesquisa, 2017.

Depreende-se do gráfico que há uma grande diferença em relação aos contos selecionados no primeiro ano do ensino médio para o terceiro ano. À proporção que o aluno-leitor progride de um ano para os outros, o conhecimento sobre o gênero literário,

Educação, Psicologia e Interfaces, Volume 2, Número 1, p. 6-21, Janeiro/Abril, 2018 
sobretudo do conto, também se amplia, ainda que seja de modo fragmentado. A tendência da proposta de ensino para o terceiro ano do ensino médio se volta para a formação do leitor literário, que pode visar à formação humanística e ao pensamento crítico e reflexivo do aluno, conforme está estabelecido na LDBEN (1996).

Ao estabelecer um paralelo das duas coleções, há que se destacar que existem muitas semelhanças no que diz respeito à abordagem dos contos, pois ambas o tratam de maneira fragmentada, propiciando uma escolarização inadequada do ensino de literatura. No entanto, vale ressaltar que elas se diferenciam quanto à quantidade de contos por ano e por coleção (Gráfico 3).

Gráfico 3 - Total de contos por ano: $1^{\circ}, 2^{\circ}, 3^{\circ}$ anos.

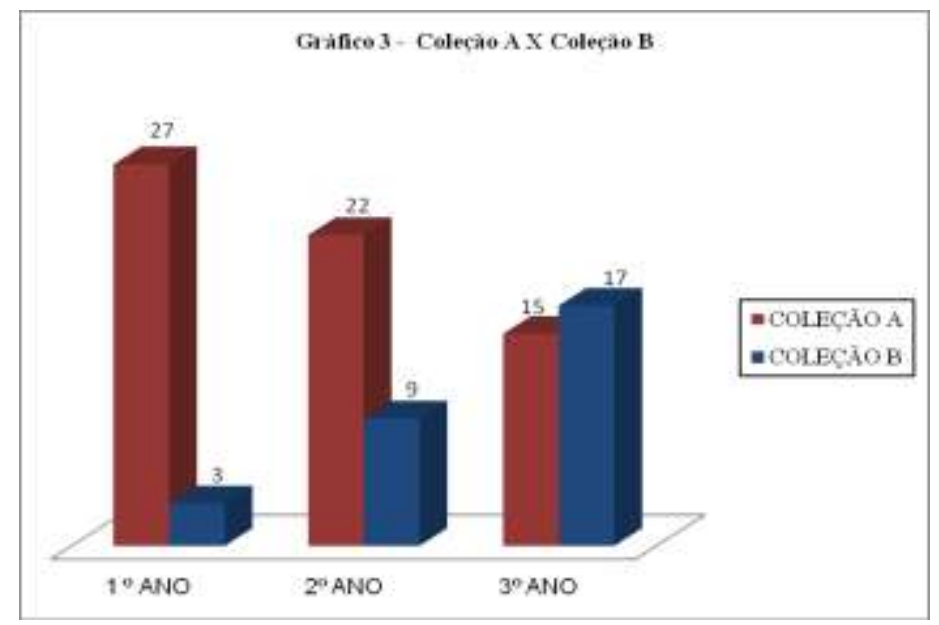

Fonte: Dados da pesquisa, 2017.

Essa diferença do total de contos por ano e por coleção esclarece, no caso da coleção A, por meio de uma ordem decrescente, e da coleção B, através de uma ordem crescente, que as perspectivas de ensino do conto seguem direcionamentos distintos. A primeira coleção, que apresenta sessenta e quatro contos em sua totalidade, indica que o ensino de literatura está voltado para o ENEM e para os vestibulares nacionais. Enquanto que da segunda coleção, com apenas vinte e nove contos, depreende-se que é no final da etapa do ensino médio que o leitor precisa possuir um número maior de leituras que o levem à construção literária de sentidos.

Para corroborar a discussão até aqui empreendida acerca da recorrência da fragmentação dos contos nos três anos do ensino médio das coleções A e B, a Tabela 1 mostra a análise dos quatro volumes referentes ao primeiro e segundo anos. No caso dos 
três anos do ensino médio da rede particular e pública, a tabela demonstra que a fragmentação dos contos, além de comprometer o sentido do texto literário, pode impossibilitar a efetivação do letramento literário.

Tabela 1 - Trabalho com o conto - Coleção A X Coleção B

$1^{\circ}$ ANO

\begin{tabular}{|c|c|c|c|c|c|}
\hline \multirow[b]{2}{*}{ Perguntas } & \multicolumn{4}{|c|}{ Coleção A } & \multirow{2}{*}{$\begin{array}{l}\text { Coleção B } \\
\text { Único }\end{array}$} \\
\hline & Volume 1 & Volume 2 & Volume 3 & Volume 4 & \\
\hline $\begin{array}{l}\text { 1. Os contos são } \\
\text { transcritos na } \\
\text { íntegra? }\end{array}$ & Parcialmente & Não & Parcialmente & Não & Sim \\
\hline $\begin{array}{l}\text { 2. Os contos são } \\
\text { transcritos em } \\
\text { fragmentos? }\end{array}$ & Sim & Sim & Sim & Sim & Sim \\
\hline $\begin{array}{l}\text { 3. } \\
\text { Caso sejam } \\
\text { transcritos } \\
\text { através de } \\
\text { excertos, eles } \\
\text { comprometem } \\
\text { a construção } \\
\text { do sentido do } \\
\text { conto? }\end{array}$ & Sim & Sim & Sim & Sim & Sim \\
\hline $\begin{array}{l}\text { 4. Os autores (e } \\
\text { obras) } \\
\text { selecionados } \\
\text { representam o } \\
\text { cânone } \\
\text { literário? }\end{array}$ & Sim & Sim & Sim & Sim & Sim \\
\hline $\begin{array}{ll}\text { 5. } & \text { Os autores (e } \\
\text { obras) } \\
\text { selecionados } \\
\text { representam a } \\
\text { tradição } \\
\text { literária não } \\
\text { canônica? }\end{array}$ & Parcialmente & Não & Parcialmente & Parcialmente & Não \\
\hline $\begin{array}{ll}6 . & \text { A coletânea de } \\
\text { textos trata da } \\
\text { teorização } \\
\text { sobre a } \\
\text { narrativa? }\end{array}$ & Não & Não & Sim & Não & Sim \\
\hline
\end{tabular}

Educação, Psicologia e Interfaces, Volume 2, Número 1, p. 6-21, Janeiro/Abril, 2018 
A literatura em livros didáticos do ensino médio à luz do letramento literário

\begin{tabular}{|c|c|c|c|c|c|}
\hline $\begin{array}{l}\text { 7. A coletânea de } \\
\text { textos trata } \\
\text { dos elementos } \\
\text { da narrativa? }\end{array}$ & Parcialme & Não & Sim & Não & Sim \\
\hline \multicolumn{6}{|c|}{$2^{\circ}$ ANO } \\
\hline \multirow[b]{2}{*}{ PERGUNTAS } & \multicolumn{4}{|l|}{ Coleção A } & Coleção B \\
\hline & Volume 1 & Volume 2 & Volume 3 & Volume 4 & Único \\
\hline $\begin{array}{l}\text { 1. Os contos são } \\
\text { transcritos na } \\
\text { íntegra? }\end{array}$ & Não & Não & Não & Não & Não \\
\hline $\begin{array}{l}\text { 2. Os contos são } \\
\text { transcritos em } \\
\text { fragmentos? }\end{array}$ & Sim & Sim & Sim & Sim & Sim \\
\hline $\begin{array}{l}\text { 3. } \\
\text { Caso sejam } \\
\text { transcritos } \\
\text { através de } \\
\text { excertos, eles } \\
\text { comprometem } \\
\text { a construção } \\
\text { do sentido do } \\
\text { conto? }\end{array}$ & Sim & Sim & Sim & Sim & Sim \\
\hline $\begin{array}{l}\text { 4. Os autores (e } \\
\text { obras) } \\
\text { selecionados } \\
\text { representam o } \\
\text { cânone } \\
\text { literário? }\end{array}$ & Sim & Sim & Sim & Sim & Sim \\
\hline $\begin{array}{ll}\text { 5. } & \text { Os autores (e } \\
\text { obras) } \\
\text { selecionados } \\
\text { representam a } \\
\text { tradição } \\
\text { literária não } \\
\text { canônica? }\end{array}$ & Não & Não & Parcialmente & Parcialmente & Sim \\
\hline $\begin{array}{ll}\text { 6. } & \text { A coletânea } \\
& \text { de textos trata } \\
\text { da teorização } \\
\text { sobre a } \\
\text { narrativa? }\end{array}$ & Não & Não & Não & Sim & Parcialmente \\
\hline $\begin{array}{ll}\text { 7. } & \text { A coletânea } \\
\text { de textos trata } \\
\text { dos elementos }\end{array}$ & Não & Não & Não & Sim & Parcialmente \\
\hline
\end{tabular}

Educação, Psicologia e Interfaces, Volume 2, Número 1, p. 6-21, Janeiro/Abril, 2018

ISSN: 2594-5343 DOI: https://doi.org/10.37444/issn-2594-5343.v2i1.59 


\begin{tabular}{|c|c|c|c|c|c|}
\hline da narrativa? & & & & & \\
\hline \multicolumn{6}{|c|}{$3^{\circ}$ ANO } \\
\hline \multirow[b]{2}{*}{ PERGUNTAS } & \multicolumn{4}{|l|}{ Coleção A } & \multirow{2}{*}{$\begin{array}{l}\text { Coleção B } \\
\text { Único }\end{array}$} \\
\hline & Volume 1 & Volume 2 & Volume $3^{1}$ & Volume 4 & \\
\hline $\begin{array}{l}\text { 1. Os contos são } \\
\text { transcritos na } \\
\text { íntegra? }\end{array}$ & Não & Parcialmente & & Parcialmente & Não \\
\hline $\begin{array}{l}\text { 2. Os contos são } \\
\text { transcritos em } \\
\text { fragmento? }\end{array}$ & Sim & Sim & & Sim & Sim \\
\hline $\begin{array}{l}\text { 3. } \text { Caso sejam } \\
\text { transcritos } \\
\text { através de } \\
\text { excertos, eles } \\
\text { comprometem } \\
\text { a construção } \\
\text { do sentido do } \\
\text { conto? }\end{array}$ & Sim & Sim & & Sim & Sim \\
\hline $\begin{array}{l}\text { 4. Os autores (e } \\
\text { obras) } \\
\text { selecionados } \\
\text { representam o } \\
\text { cânone } \\
\text { literário? }\end{array}$ & Sim & Sim & & Sim & Sim \\
\hline $\begin{array}{ll}\text { 5. } & \text { Os autores (e } \\
\text { obras) } \\
\text { selecionados } \\
\text { representam a } \\
\text { tradição } \\
\text { literária não } \\
\text { canônica? }\end{array}$ & Não & Sim & & Não & Sim \\
\hline $\begin{array}{ll}\text { 6. } & \text { A coletânea } \\
\text { de textos trata } \\
\text { da teorização } \\
\text { sobre a } \\
\text { narrativa? }\end{array}$ & Não & Sim & & Parcialmente & Sim \\
\hline $\begin{array}{ll}\text { 7. } & \text { A coletânea } \\
\text { de textos trata } \\
\text { dos elementos }\end{array}$ & Não & Sim & & Parcialmente & Sim \\
\hline
\end{tabular}

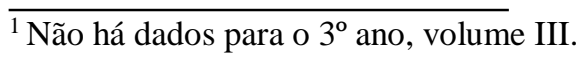

Educação, Psicologia e Interfaces, Volume 2, Número 1, p. 6-21, Janeiro/Abril, 2018 
\begin{tabular}{l|l|l|l|l|l}
\hline da narrativa? & & & & & \\
\hline
\end{tabular}

Fonte: Dados da pesquisa, 2017.

Em relação aos itens 1 e 2 da Tabela 1, é possível apontar que todos os volumes das coleções A e B possuem contos mediante excertos e poucos são os volumes que têm estes textos literários na íntegra. Devido à recorrência da fragmentação dos contos, o item 3, que diz respeito ao comprometimento do sentido deles, apresenta sim em todos os volumes. Já o item 5 que trata dos autores da tradição literária não canônica não está contemplado em todos os volumes, o que se diferencia do item 4 que remete aos textos que representam o cânone literário e está presente em todos os volumes. Isso pode ser decorrente da orientação das OCEM (2006) e dos PCNEM (2002) ao enfatizarem o estudo da literatura por intermédio do cânone ocidental.

De um modo geral, esta tabela revela que predominam, em todos os volumes da coleção A, os contos por meio de trechos, o estudo da tradição literária canônica, além de se referir muito pouco à teorização da narrativa e aos elementos desta. Essa situação também se aproxima do que ocorre na coleção B, pois os contos não são ensinados em sua integralidade, o que afeta a construção literária de sentidos. Ademais, percebe-se que, como a coleção da rede pública apresenta poucos contos, é possível verificar que as propostas fazem referência aos elementos e à estrutura do texto narrativo, enquanto os volumes da rede particular se diferenciam quanto a esse assunto, alguns tratam da teoria do conto e outros não.

Ao fazer um recorte do primeiro ano do ensino médio e do terceiro de ambas as coleções didáticas, observa-se que o fato de o letramento literário não se concretizar ao final do ensino médio na coleção da rede particular pode ser bem maior do que na da rede pública. Enquanto o ensino particular centra-se em questões de múltipla escolha e excesso de explicações teóricas sobre os conteúdos de ensino relacionados à literatura, o ensino público se preocupa com as questões discursivas que primam pela subjetividade do leitor.

Em suma, é importante considerar que, embora o gênero conto seja ensinado mediante trechos que impossibilitam ao leitor apropriar-se da literatura como um processo de construção de sentidos, a coleção B conduz o leitor, de modo gradativo, aos contos, ampliando, assim, o seu conhecimento literário até o final do ensino médio. $\mathrm{O}$ que ocorre, diferentemente, na coleção A, uma vez que esta tende a reduzir a variedade

Educação, Psicologia e Interfaces, Volume 2, Número 1, p. 6-21, Janeiro/Abril, 2018 
de contos que devem estar presentes na vida do leitor enquanto experiência estética e até mesmo de humanização.

\section{CONSIDERAÇÕES FINAIS}

Tendo como base a análise dos dados e as discussões que foram tecidas acerca do ensino de literatura, verificou-se que o gênero literário conto adquiriu destaque nos desdobramentos dessa pesquisa devido a sua brevidade e proximidade com o leitor no sentido de formá-lo literariamente. A tendência do seu ensino deveria primar pelo contexto sócio-histórico e cultural da literatura, com o intuito de não permitir que o aluno-leitor perda a sua subjetividade que lhe é garantida pela leitura literária.

Já no que diz respeito à coleção $\mathrm{B}$, depreendeu-se que a proposta para o ensino de Língua Portuguesa se efetiva por meio dos critérios estabelecidos pelos parâmetros oficiais. Contudo, no quesito dos conteúdos de ensino de literatura, observou-se que o problema está centrado no campo da constituição do leitor literário, assim como da formação crítica e reflexiva desse leitor e do letramento literário que fica prejudicado, à medida que o gênero conto, objeto dessa pesquisa, se expressa por meio de trechos que não contemplam o sentido integral da obra literária.

Em ambas as coleções didáticas, a metodologia de ensino do conto pode impossibilitar a concretização do letramento literário, conforme prevê os documentos que regem o ensino de Língua Portuguesa. Todavia, é preciso acrescentar que elas se diferenciam quanto a sua estruturação, pois enquanto a coleção A é organizada em volumes por ano, a coleção B apresenta um único volume para cada ano do ensino médio.

Outra diferença premente entre elas é que, embora o enfoque de ambas seja direcionar o ensino de literatura, de modo específico para o Exame Nacional do Ensino Médio - ENEM - a primeira está mais centrada em questões de múltipla escolha que, de modo reiterado, inviabiliza a construção de sentidos dos textos. Já a segunda apresenta outro direcionamento para as questões, pois elas são discursivas, o que leva à experiência estética, ainda que seja por meio dos fragmentos dos contos que não condensam a totalidade do sentido da obra em estudo.

Como as propostas de leitura literária não priorizam o prazer, é importante apresentar a literatura de outra forma para o aluno, priorizando uma experiência estética

Educação, Psicologia e Interfaces, Volume 2, Número 1, p. 6-21, Janeiro/Abril, 2018 
com o texto literário. No entanto, para que isso seja possível, é preciso que o professor trabalhe com a linguagem literária e com a noção de que aquele mundo encenado na narrativa é o mundo do aluno mimetizado. Embora o livro didático não tenha como colocar todos os textos literários na íntegra, o trabalho com o conto deve ganhar uma atenção especial dos professores, estudiosos e daqueles que produzem materiais didáticos, visto que é uma "forma breve" que pode, ao contrário de uma epopeia e um romance, ser trabalhado integralmente no livro didático.

Portanto, essa pesquisa contribui para a discussão sobre a formação do leitor literário e a orientação dos conteúdos de ensino de literatura nos anos do ensino médio por meio dos livros didáticos. Como bem destaca a BNCC (2016), o letramento literário deve seguir até o ensino médio, cuja etapa de ensino é de grande valia para a formação do pensamento crítico e reflexivo do leitor. É preciso que os materiais didáticos se preocupem em ensinar ao aluno os conteúdos em sua integralidade, pois, caso contrário, ele não conseguirá aprender criticamente e se apropriar do conhecimento literário, por exemplo, para a sua formação humana.

\section{REFERÊNCIAS BIBLIOGRÁFICAS}

ABAURRE, M. L. M. et al. Português: contexto, interlocução e sentido. $1^{\text {a }}$ série, Língua Portuguesa, Ensino Médio. São Paulo: Moderna, 2013.

Português: contexto, interlocução e sentido. $2^{\mathrm{a}}$ série, Língua Portuguesa, Ensino Médio. São Paulo: Moderna, 2013.

Português: contexto, interlocução e sentido. $3^{\mathrm{a}}$ série, Língua Portuguesa, Ensino Médio. São Paulo: Moderna, 2013.

ASSOCIAÇÃO BRASILEIRA DE NORMAS TÉCNICAS. NBR 14724: informação e documentação: trabalhos acadêmicos: apresentação. Rio de Janeiro, 2011. BRASIL. MEC. SECRETARIA DE EDUCAÇÃ̂ BÁSICA. Base Nacional Comum Curricular. Brasília: MEC/SEB, 2016.

BENJAMIN, W. O narrador: considerações sobre a obra de Nikolai Leskov. In: Magia e técnica, arte e política: Ensaios sobre literatura e história da cultura. Tradução Sergio Paulo Rouanet. 3. ed. São Paulo: Brasiliense, 1987, p. 197-221.

BRASIL. MEC. SECRETARIA DE EDUCAÇÃO BÁSICA. Base Nacional Comum Curricular. Brasília: MEC/SEB, 2016. 
Lei de Diretrizes e Bases da Educação Nacional. Lei número 9394, 20 de dezembro de 1996.

SECRETARIA DE EDUCAÇÃO BÁSICA. Linguagens, Códigos e suas

Tecnologias. Brasília: MEC/SEB, 2006.

MEC. SECRETARIA DE EDUCAÇÃO MÉDIA E TECNOLÓGICA SEMTEC. PCN+ Ensino Médio -Orientações Educacionais Complementares aos Parâmetros Curriculares Nacionais -Linguagens, Códigos e suas Tecnologias. Brasília: MEC; SEMTEC, 2002. . MEC. FUNDO NACIONAL DE DESENVOLVIMENTO DA EDUCAÇÃO. Programa Nacional do Livro Didático. Brasília: MEC/FNDE, 2015.

CANDIDO, A. O direito à literatura. In: São Paulo: Duas Cidades, 1995, p. 235-263. . Vários escritos. 3. ed. rev. e ampl.

COSSON, R. Letramento literário: teoria e prática. São Paulo: Contexto, 2014a. Círculos de leitura e letramento literário. São Paulo: Contexto, 2014b.

COSTA, M. M. da. Leitura, literatura e aprendizagem. In: e aprendizagem. Curitiba, PR: IESDE Brasil S. A., 2009. p. 11-21. Literatura, leitura

GIL, A. C. Métodos e técnicas de pesquisa social. 6. ed. São Paulo: Atlas, 2008.

PIGLIA, R. Novas teses sobre o conto. In: Formas breves. Tradução José Marcos Mariani de Macedo. São Paulo: Companhia das Letras, 2004, p. 97-114.

Teses sobre o conto. In: Formas breves. Tradução José Marcos Mariani de Macedo. São Paulo: Companhia das Letras, 2004, p. 89-94.

ROQUE, F. et al. Coleção Estudo - Língua Portuguesa. EM 1, v. I, II, III, IV. Língua Portuguesa, Ensino Médio. Belo Horizonte: Bernoulli Sistema de Ensino, 2016.

. Coleção Estudo - Língua Portuguesa. EM 2, v. I, II, III, IV. Língua

Portuguesa, Ensino Médio. Belo Horizonte: Bernoulli Sistema de Ensino, 2016.

Coleção Estudo - Língua Portuguesa. EM 3, v. I, II, III, IV. Língua

Portuguesa, Ensino Médio. Belo Horizonte: Bernoulli Sistema de Ensino, 2016.

SOARES, M. A escolarização da literatura infantil e juvenil. In: MARTINS, A. A.; BRANDÃO, H. M. B.; MACHADO, M. Z. V. (Org.). Escolarização da leitura literária. Belo Horizonte: Autêntica, 1999, p. 17-48.

TODOROV, T. A literatura em perigo. Rio de Janeiro: DIFEL, 2010. 


\section{Credenciais das autoras}

MAIA, Cláudia Fernanda Freitas. Graduada em Letras Português pela Unimontes, Mestra em Educação pela Universidade Federal dos Vales do Jequitinhonha e Mucuri UFVJM - MG/Brasil. E-mail: nandamaia8@gmail.com.

SANTOS, Rosana Baptista dos. Doutora em Literatura Comparada pela Universidade Federal de Minas Gerais, professora na Universidade Federal dos Vales do Jequitinhonha e Mucuri -UFVJM -MG/Brasil. E-mail:

rosanabaptistasantos@gmail.com .

Endereço para correspondência: Cláudia Fernanda Freitas Maia. Rua José Gomes, n. 279, Conjunto José Carlos de Lima, CEP: 39402-350, Cidade Montes Claros, MG. Email: nandamaia8@gmail.com

Como citar este artigo (Formato ABNT): MAIA, Cláudia Fernanda Freitas; SANTOS, Rosana Baptista dos. A literatura em livros didáticos do ensino médio à luz do letramento literário. Educação, Psicologia e Interfaces, v. 2, n.1, p. 6-21, 2018. DOI: https://doi.org/10.37444/issn-2594-5343.v2i1.59

Recebido: 07/02/2018.

Aceito: 26/03/2018. 